\title{
Psychological stress and coeliac disease in childhood: a cohort study
}

\author{
Karl Mårild ${ }^{1,2^{*}}$, Anneli Sepa Frostell ${ }^{3}$, Jonas F Ludvigsson ${ }^{4,5}$
}

\begin{abstract}
Background: Psychological stress has previously been associated with several immunological diseases, e.g. inflammatory bowel disease. Through questionnaire data from the ABIS study (All Babies In southeast Sweden) we examined the association between psychological stress in the family and biopsy-proven coeliac disease (CD) in the child.

Methods: We used serious life event, parenting stress, and parental worries as measures of psychological stress. Data were collected when the child was 1 and 2.5 years old in some 11,000 and 8,800 children, respectively. CD was confirmed through small intestinal biopsy (with villous atrophy), and the diagnosis was validated through patient chart data.
\end{abstract}

Results: Serious life event in the family in the child's first 1 or 2.5 years after childbirth was not associated with future CD in the child (Odds Ratio (OR) $=0.45 ; 95 \%$ Confidence Interval $(C \mathrm{l})=0.01-2.65 ; P=0.72$; and $\mathrm{OR}=1.21$; $95 \% \mathrm{Cl}=0.43-3.05 ; P=0.64$, respectively). Neither did we see any association between $C D$ and parenting stress at age 1 year and at 2.5 years $(\mathrm{OR}=0.40 ; 95 \% \mathrm{Cl}=0.01-2.38 ; P=0.73$ and $\mathrm{OR}=0.74 ; 95 \% \mathrm{Cl}=0.01-4.56 ; P=1.00$, respectively). Among children exposed to parental worries at 2.5 years, no child had a diagnosis of $C D$ before end of follow-up, compared to 25/8082 (0.3\%) among non-exposed children $(\mathrm{OR}=0.00 ; 95 \% \mathrm{Cl}=0.00-2.34 ; P=0.64)$. There was no association between the combined measures of stress and CD.

Conclusion: This study found no association between psychological stress and later development of CD in Swedish children. However, we cannot rule out that the lack of such an association is due to limited statistical power.

\section{Background}

Coeliac disease $(C D)$ is an immunological disorder induced by gluten exposure. It is a multi-factorial disease characterized by small intestinal villous atrophy [1]. Previous studies have suggested that environmental factors in early life influence the risk of $C D$, e.g. the amount [2] and timing of gluten introduction [3]. It has been proposed that the first period of life may include a vulnerable timeframe, where environmental factors could influence the immune system and the risk of $C D$ in childhood [4]. The proportion of CD cases identified through screening has increased during the last decades. This suggests that still unknown environmental factors remain to be identified [5].

\footnotetext{
* Correspondence: karlmarild@gmail.com

'Astrid Lindgren Children's Hospital, Karolinska University Hospital, Solna, Sweden

Full list of author information is available at the end of the article
}

Psychological stress is an environmental factor that has been associated with several immunological diseases, e.g. inflammatory bowel disease [6], allergic disease [7], and atopic dermatitis [8]. Psychological stress has a direct effect on a variety of immunological mechanisms, including the functional profile of T-cells and several immune-inflammatory markers $[9,10]$.

In 2005, Sepa et al [11] suggested that maternal exposure to serious life events after childbirth increases the risk of diabetes-related autoimmunity in the offspring. Type 1 diabetes mellitus (T1D) and CD are closely associated [12], and the patients share similar HLA alleles, epidemiological features [13] and partially common infant feeding risk factors $[3,14,15]$. However an earlier study of pregnancy-related stress found no relationship between psychological stress in mothers during pregnancy and development of CD in the offspring [16]. In the current study, we examined the risk of $C D$ in 
children to parents with high level of stress after birth. For this purpose we examined prospectively collected data on psychological stress in 73 children with biopsyverified $C D$. This study was part of the ABIS project (All Babies in Southeast Sweden).

\section{Methods}

\section{Description of the ABIS study}

From October 1997 through October 1999, parents to babies born in southeast Sweden were invited to participate in the ABIS cohort project. This project examines the role of environmental factors for the development of autoimmune and allergic diseases. Of the 21,700 babies born during the study period, the parents of 17,055 children (78.6\%) gave their informed consent to participate. In the maternity ward, the mothers received an at-birth questionnaire that was completed by 16,070 mothers. Of the 10,932 that participated in the 2.5-year follow-up, 8,805 completed the 2.5-years-questionnarie. Study participants [17] were more often born in Sweden, compared to the general population. We compared prospectively assessed measures of stress between children with $C D$ with those without a diagnosis of $\mathrm{CD}$.

\section{Definition of CD}

Data on CD were collected on two occasions. The majority of children with $C D$ were identified through a study on symptoms and signs in CD [18]. In 2007-2008, we again contacted the same eight paediatric departments participating in the study published in 2004 [18] and asked them to report additional ABIS children with biopsy-verified CD (partial or subtotal-total villous atrophy) diagnosed before $1^{\text {st }}$ Dec 2006 . For this diagnosis we also requested symptoms/signs and antibody markers consistent with the diagnosis of $\mathrm{CD}$ (for further details, see earlier study [18]). In the current study, date of CD diagnosis equals date of first positive small intestinal biopsy. The ABIS child population was not actively screened for $\mathrm{CD}$, and we do not have population-based data on CD serology in study participants. Hence, cases of $\mathrm{CD}$ were diagnosed due to symptoms, and signs, or through screening for clinical (i.e. non-research) purposes.

We identified 83 children with CD, 10 of these were diagnosed before age 1 year and excluded from the analyses since the diagnosis per se might have influenced the way the parents responded to the questions about stress and life events occurring within the first year of life. The remaining 73 were included in all analyses referring to stress until age 1 year, of these 43 were diagnosed after 2.5 year of age and were also included in the analyses referring to stress until age 2.5 year.

\section{Definition of psychological stress}

Three domains concerning psychological stress were assessed: 1) Exposure to a serious life event in the family was assessed at 1 and 2.5 years of age with the following two yes/no questions: At 1 year of age we asked: "Has your child been exposed to something which you perceive as a serious life event since his/her birth?". At 2.5 years of age we asked: "Have you [the parent] been exposed to something which you perceive as a serious life event since you're child's birth?". Examples given were death of a relative, serious disease in the family, serious accident in the family, divorce, exposure to violence, and unemployment. We had data on serious life event in 10,541 children $(447 ; 4.2 \%$ had been exposed) in the first year of life, and in 8,722 children until age 2.5 years $(2,119 ; 24.3 \%$ exposed). 2) Parenting stress was assessed at 1 and 2.5 years of age with the Swedish Parenting Stress Questionnaire (SPSQ) [19], which has a good validity and good stability [19]. In our sample Chronbach's alpha was 0.88 at age 1 and 0.89 at age 2.5. SPSQ consists of 34 items tapping the dimensions incompetence (11 items), spouse relationship problems (5 items), role restriction (7 items), social isolation (7 items), and health problems (4 items). On each item a 6-point Likert-type response scale was used ranging from "strongly disagree" to "strongly agree". A mean value was calculated if less than six items were missing. Dichotomized variables were created using the $95^{\text {th }}$ percentile as a cut-off, defining exposure to parenting stress at each age. 3) Parental worries were assessed at 2.5 years of age with six items, each describing a potential risk for the child (i.e. that the child falls seriously ill, is harmed, is going to be handicapped, is not going to develop normally, is going to be exposed to abuse, and is not going to survive). For each item the parent estimated on a 6-point Likert-type response scale ranging from "very calm" to "very worried" how worried they were that their child might become affected. Chronbach's alpha was 0.89 in our sample. Mean values for answered items (if one or no item was missing) above the $95^{\text {th }}$ percentile defined exposure to parental worries.

Finally, a composite measure of psychological stress at age 2.5 was created (from 8,369 children) in order to estimate the overall amount of stress experienced in the family, by counting in how many of the domains the child had been exposed to stress at age 2.5 (composite measures of this kind have been used in e.g. the papers by Ostberg et al [20] and Wekerle et al [21]). If a child had not been exposed in any of the domains the score for the composite measure was 0 and if the child had been exposed in all three domains the score was 3 . Since only 11 children had been exposed in all three domains, they were grouped together with those 
exposed in two domains. This group will onwards be referred to as children exposed to high stress in the family.

\section{Statistics}

To avoid potential recall bias, we excluded individuals with a diagnosis of $\mathrm{CD}$ before the age of 1 year from our main analyses (since knowledge of $\mathrm{CD}$ in one's child might have influenced the way the questionnaires were completed by parents) (and before 2.5 years of age in relevant analyses). Hence follow-up began at 1 year of age.

Chi-2 test, and when appropriate Fisher' exact test, and logistic regression estimated the association between the psychological stress variables and CD. Exact odds ratios (OR) and 95\% confidence intervals (CI) were calculated to compare children 'exposed' and 'not exposed' concerning each psychological stress domain, respectively, as well as for comparing 'not exposed', 'exposed in one domain', and 'high stress in the family' (i.e. exposed in at least two domains) for the composite measure. The dependent variables in the analyses were $\mathrm{CD}$ after age 1 year $(n=73), \mathrm{CD}$ after age 2.5 years $(n=43)$, and ever having a diagnosis of CD $(n=83)$. Due to lack of data on stress (not all study participants filled out the questionnaires at 1 year and 2.5 years of age or all questions in the questionnaires), the actual number of children with $C D$ included in the analyses was lower (1 year: $n=48-51 ; 2.5$ year: $n=24-26$ ).

Since earlier data have suggested that breastfeeding pattern may influence the risk of $\mathrm{CD}$ [2], we chose to adjust for breastfeeding duration in a number of posthoc analyses. We had data on duration of breastfeeding in 8,428 individuals. Children were divided into four categories ( $\leq 90$ days, 91-180 days, 181-270 days and $\geq 271$ days of breastfeeding). In individual analyses, numbers may be lower due to missing data on outcome measures.

Statistical significance was defined as $95 \% \mathrm{CI}$ for estimates not including 1.0 and $\mathrm{p}<0.05$. We used SPSS 15.0 to perform the analyses.

\section{Ethics}

This study was part of the ABIS study, which has been approved by the Research Ethics Committees of the Faculty of Health Sciences, Linkoping University, and the Medical Faculty of Lund University. Mothers gave their consent after careful written as well as oral information and information via videotape.

\section{Results}

\section{Background data}

More than $70 \%$ of patients with CD were girls compared to about $48 \%$ in those without a diagnosis of CD (see
Additional file 1). A family history of T1 D and CD was more common among children with $\mathrm{CD}$ compared to the reference group. The children were followed-up until Dec $1^{\text {st }} 2006$, which corresponded to 8 years of age in the average participant. The mean maternal age at childbirth was close to 30 years.

\section{Serious life event}

Out of 10,541 children, 447 had experienced at least one serious life event during their first year of life according to questionnaire data (Table 1 ). Only $1 / 447$ exposed to a serious life event developed $\mathrm{CD}$. This corresponded to an OR for future CD of $0.45(95 \% \mathrm{CI}=0.01-2.65 ; P=$ 0.72 ). At 2.5 years of life $2,119 / 8,722$ reported that they had experienced a least one serious life event (Table 2). Seven children whose parent had experienced a serious life event had a later diagnosis of $\mathrm{CD}(0.33 \%)$, compared to $18(0.27 \%)$ children without a parental experience of serious life event. Serious life event in the first 2.5 years of life was hence no risk factor for future CD (OR = 1.21; $95 \% \mathrm{CI}=0.43-3.05 ; P=0.64$ ).

\section{Parenting stress}

Only $1 / 525$ children exposed to such stress developed CD (0.19\%) (compared with 47 non-exposed children who developed CD (0.47\%); Table 1). OR for CD in children exposed to parenting stress at age 1 was 0.40 (95\% $\mathrm{CI}=0.01-2.38 ; P=0.73)$. The corresponding $\mathrm{OR}$ at 2.5 years was $0.74(95 \% \mathrm{CI}=0.01-4.56 ; P=1.00)($ Table 2$)$.

\section{Parental worries}

In 438 children (out of 8,520), parents had reported worries in the first 2.5 years of life. None of these

Table 1 Psychological stress at age 1 and risk of future coeliac disease (CD)

\begin{tabular}{|c|c|c|c|c|c|}
\hline & \multicolumn{5}{|c|}{$\begin{array}{c}\text { Crude odds ratios (OR) for coeliac disease } \\
\text { diagnosed after age } 1\end{array}$} \\
\hline & $n *$ & $n$ with $C D$ & OR & $95 \% \mathrm{Cl}$ & $P$ \\
\hline $\begin{array}{c}\text { Serious life event at } \\
\text { age } 1 \S \\
\end{array}$ & & & & & 0.72 \\
\hline No serious life event & 10094 & 50 & reference & & \\
\hline A Serious life event & 447 & 1 & 0.45 & $0.01-2.65$ & \\
\hline
\end{tabular}

\begin{tabular}{cccccc}
\hline $\begin{array}{c}\text { Parenting stress at } \\
\text { age } \mathbf{1} \S\end{array}$ & & & & 0.73 \\
\hline Non-exposed & 9989 & 47 & reference & \\
\hline Exposed & 525 & 1 & 0.40 & $0.01-2.38$ \\
\hline
\end{tabular}

*Number of parents answering the questionnaire questions referring to serious life event and parenting stress, respectively. Due to internal attrition the numbers of reference individuals vary between the different analyses. $\S$ For definition of serious life event and parenting stress, see text.

$\mathrm{Cl}=$ Confidence interval according to exact test. P-values were calculated using Fisher's exact test. 
Table 2 Psychological stress at age 2.5 years and risk of future coeliac disease (CD)

\begin{tabular}{|c|c|c|c|c|c|}
\hline & \multicolumn{5}{|c|}{ Crude odds ratios (OR) for coeliac disease diagnosed after age 2.5} \\
\hline & $n^{*}$ & $n$ with CD & OR & $95 \% \mathrm{Cl}$ & $P$ \\
\hline Serious life event at age $2.5 \S$ & & & & & 0.64 \\
\hline No serious life event & 6603 & 18 & reference & & \\
\hline A Serious life event & 2119 & 7 & 1.21 & $0.43-3.05$ & \\
\hline Parenting stress at age $2.5 \S$ & & & & & 1.00 \\
\hline Non-exposed & 8202 & 25 & reference & & \\
\hline Exposed & 442 & 1 & 0.74 & $0.01-4.56$ & \\
\hline Parental worries at age $2.5 \S$ & & & & & 0.64 \\
\hline Non-exposed & 8082 & 25 & reference & & \\
\hline Exposed & 438 & 0 & 0.00 & $0.00-2.34$ & \\
\hline \multicolumn{6}{|l|}{ Composite measure at age $2.5 \S$} \\
\hline Non-exposed & 5837 & 18 & reference & & \\
\hline Exposed in one domain & 2232 & 5 & 0.73 & $0.21-2.03$ & 0.64 \\
\hline High stress in the family & 300 & 1 & 1.08 & $0.03-6.89$ & 0.61 \\
\hline \multicolumn{6}{|c|}{$\begin{array}{l}\text { *Number of parents answering the questionnaire questions referring to serious life event, parenting stress and parental worries, respectively. Due to internal } \\
\text { attrition the numbers of reference individual vary between the different analyses. }\end{array}$} \\
\hline (a) & & & & & \\
\hline
\end{tabular}

children later developed CD (compared with 25 nonexposed children). CD was hence not associated with parental worries during the first 2.5 year of life (Table 2). When we included all individuals with CD, also those with a diagnosis prior to the 1-year-questionnaire there was still no association between parental worries and $C D(O R=0.80 ; 95 \% C I=0.09-3.08$; $P=1.00)$.

\section{Composite measure of psychological stress}

In a final analysis we used logistic regression to estimate the association between a composite measure of psychological stress across three different domains (serious life event, parenting stress and parental worries) and CD. However, CD was not associated with stress in one or more domains (Table 2).

Post-hoc analyses adjusting for duration of breastfeeding Adjustment for duration of breastfeeding did not influence any of the above risk estimates more than marginally (complete data not shown). E.g. there were no increased risk of future $\mathrm{CD}$ in individuals with a serious life event at age 1 (adjusted OR $=0.61 ; 95 \% \mathrm{CI}=0.08$ 4.47; $P=0.63$ ), parenting stress at age 1 (adjusted $\mathrm{OR}=$ $0.54 ; 95 \% \mathrm{CI}=0.07-3.94 ; P=0.54$ ), or composite measure of high stress in the family at age 2.5 (adjusted OR $=1.35 ; 95 \% \mathrm{CI}=0.18-10.26 ; P=0.77)$.

\section{Discussion}

In the current study we examined the association between psychological stress in the family (measured as serious life event, parenting stress, and parental worries, respectively and combined), and biopsy-proven $C D$ in the child. There was no statistically significant association between prospectively assessed exposure to psychological stress in the family and later development of CD in the child. However, due to small numbers we cannot rule out that early infant stress may nevertheless considerably influence the risk of CD.

A major strength of our population-based study is its prospective design, where data on stress were collected prior to the diagnosis of CD. This fact eliminates the risk of recall bias dependent on $C D$ status. The $C D$ diagnosis was based on small intestinal biopsy (with villous atrophy) and validated through review of patient chart data supplied from the responsible physicians at each of the eight paediatric departments caring for CD in the study area. Hence, the risk of misclassification is low. Another strength is our use of a validated scale to measure parenting stress (Swedish Parenthood Stress Questionnaire (SPSQ)) [19].

Similar to most other prospective cohort studies, the study suffers from some drop-out. At 2.5 years of age, half of the population entering the study at birth completed the relevant questionnaire. Although, we cannot 
rule out the existence of bias, our study design guarantees that such potential bias is independent of CD status. It has been shown that the participants in the ABIS study cohort have a slightly lower proportion of mothers with foreign origin and a slight under representation of parents with low education compared to the general Swedish population [11].

Children in this study were on average followed up until 8 years of age. It is likely that some individuals have a diagnosis of $\mathrm{CD}$ after that age, but given the prevalence of $C D$ in our dataset, we assume that a large share of individuals with diagnosed $C D$ will have received their diagnosis before age 9 years. And there is little reason to believe that parental stress in the first 12 years of life will not affect the risk of $C D$ in the first 8 years, but well beyond that age. Of greater concern is that we have not been able to screen the ABIS cohort for $\mathrm{CD}$, and our patients only consist of individuals with diagnosed $\mathrm{CD}$. That is however only a problem if risk factors differ between individuals with or without symptoms, and individuals with or without high disease activity (meriting investigation for CD in childhood). Although, we cannot rule out that the inclusion of undiagnosed $\mathrm{CD}$ would have altered our risk estimate; psychological stress in the family is unlikely to be a major risk factor for $\mathrm{CD}$, since it does not influence the risk of diagnosed $C D$ at all (see results section). Meanwhile, the inclusion of false-negative $C D$ cases among controls in this study will not affect risk estimates since the prevalence of undiagnosed CD should not exceed $1 \%$ [22].

One weakness of this study is the lack of means to directly measure the psychological stress in the child. Instead this study, like earlier research [11,17], used psychological stress in the family, assessed by the parent, as a marker for stress in the child. Although psychological stress in the family is most likely to influence the child's wellbeing and experience of stress, we cannot rule out that this indirect measure of psychological stress have changed our risk estimates and increased the risk of a type 2 error. Due to internal attrition the actual number of children with $\mathrm{CD}$ included in the analyses was low (1 year: $n=48-51 ; 2.5$ year: $n=24-26$ ), which also contributed to an increased risk of a type 2 error (i.e. to erroneously accept a false null hypothesis).

In a negative trial, like this one, the clinical significance of a potential type 2 error must be remembered. We cannot rule out that we have failed to observe a difference in the risk of CD between exposed and unexposed children due to lack of study power. Some of the summary risk estimates in this study are below one and, although far from statistical significant, may even indicate a negative association (i.e. a protective effect) between psychological stress and $\mathrm{CD}$. This study cannot rule out that non-exposed children are at a highly increased relative risk of future $C D$, however, the baseline prevalence of $\mathrm{CD}$ in this group was still only $0.31 \%$.

Data on the protective effect of breastfeeding on the risk of $C D$ are conflicting $[2,3,23]$. Earlier data on the ABIS children [24] have shown no association between duration of breastfeeding and CD status (See Methods). In a number of post-hoc analyses we still chose to adjust for duration of breastfeeding, but with only marginally changed risk estimates. Low socioeconomic status (e.g. level of education) and maternal age have been suggested to be associated with parenting stress [25]. However, in this study there was no significant difference in maternal age or level of education according to $\mathrm{CD}$ status (univariate analyses) hence they we did not adjust for these values [26].

Earlier data suggest a positive association between psychological stress and a number of diseases $[27,28]$ including T1D-related autoimmunity [29]. T1 D shares many etiological traits with CD [30] including shared infant feeding risk factors $[3,14,15]$, occurrence of similar autoantibodies [12] and a shared genetic susceptibility [31]. CD and T1 D also share certain epidemiological features, and the prevalence of $\mathrm{CD}$ among patients with $\mathrm{T} 1 \mathrm{D}$ is estimated to be in the range of 3-6\% [22]. Using prospectively collected data from the ABIS study, Sepa et al $[11,17]$ found an association between mothers' experience of psychological stress and diabetes-related autoimmunity in their children in infancy and at age 2.5 years. Based on other data from the ABIS study, Ludvigsson and Ludvigsson failed to show any association between pregnancy-related stress in the mother and risk of $\mathrm{CD}$ in the offspring [16].

\section{Conclusions}

The results of the current study are consistent with our earlier data on stress and CD, and we found no statistically significant association between psychological stress in the family in the first 2.5 years of life and future $C D$ in childhood. However, we cannot rule out that the lack of such an association is due to limited statistical power.

\section{Additional material}

Additional file 1: Background characteristics of the ABIS study

cohort according to presence of future coeliac disease (CD).

\section{List of abbreviations}

ABIS: all Babies in Southeast Sweden; CD: coeliac disease; Cl: confidence interval; OR: odds ratio; SPSQ: Swedish parenting stress questionnaire; TID: type 1 diabetes mellitus. 


\section{Acknowledgements}

The authors thank the ABIS study group and professor Johnny Ludvigsson (Linköping, Sweden), initiator of the ABIS project.

This project was supported by a grant from The Swedish Society of Medicine, the Swedish Research Council, the Sven Jerring Foundation, the Örebro Society of Medicine, the Karolinska Institutet, the Clas Groschinsky Foundation, the Juhlin Foundation, the Majblomman Foundation, UppsalaÖrebro Regional Research Council and the Swedish Coeliac Society. Grant support (for manuscript preparation): KM: the Örebro University Hospital Research Committee. AF: the Swedish Research Council. JFL was supported by a grant from the Örebro University Hospital while supervising this article.

\section{Author details}

'Astrid Lindgren Children's Hospital, Karolinska University Hospital, Solna, Sweden. ${ }^{2}$ Department of Medicine, Örebro University, Örebro, Sweden. ${ }^{3}$ Department of Clinical and Experimental Medicine, Division of Paediatrics and Diabetes Research Centre, Linköping University, Sweden. ${ }^{4}$ Clinical Epidemiology Unit, Department of Medicine, Karolinska Institutet, Stockholm, Sweden. ${ }^{5}$ Department of Paediatrics, Örebro University Hospital, Örebro, Sweden.

\section{Authors' contributions}

KM wrote the manuscript and contributed to the study design. AF contributed with knowledge on stress and the instruments to measure stress, she also performed the statistical analyses. JFL initiated and designed the study. AF and JFL critical reviewed the manuscript. All authors read and approved the final manuscript.

\section{Competing interests}

The authors declare that they have no competing interests.

Received: 24 August 2009 Accepted: 14 September 2010

Published: 14 September 2010

\section{References}

1. Green PH, Cellier C: Celiac disease. N Engl J Med 2007, 357:1731-1743,

2. Ivarsson A, Hernell O, Stenlund H, Persson LA: Breast-feeding protects against celiac disease. Am J Clin Nutr 2002, 75:914-921.

3. Norris JM, Barriga K, Hoffenberg EJ, Taki I, Miao D, Haas JE, Emery LM, Sokol RJ, Erlich HA, Eisenbarth GS, Rewers M: Risk of celiac disease autoimmunity and timing of gluten introduction in the diet of infants at increased risk of disease. Jama 2005, 293:2343-2351.

4. Guandalini S, Setty M: Celiac disease. Curr Opin Gastroenterol 2008, 24:707-712.

5. Lohi S, Mustalahti K, Kaukinen K, Laurila K, Collin P, Rissanen H, Lohi O, Bravi E, Gasparin M, Reunanen A, Maki M: Increasing prevalence of coeliac disease over time. Aliment Pharmacol Ther 2007, 26:1217-1225.

6. Mawdsley JE, Rampton DS: Psychological stress in IBD: new insights into pathogenic and therapeutic implications. Gut 2005, 54:1481-1491.

7. Montoro J, Mullol J, Jauregui I, Davila I, Ferrer M, Bartra J, del Cuvillo A, Sastre J, Valero A: Stress and allergy. J Investig Allergol Clin Immunol 2009, 19(Suppl 1):40-47.

8. Arndt J, Smith N, Tausk F: Stress and atopic dermatitis. Curr Allergy Asthma Rep 2008, 8:312-317.

9. Marshall GD Jr, Agarwal SK, Lloyd C, Cohen L, Henninger EM, Morris GJ: Cytokine dysregulation associated with exam stress in healthy medical students. Brain Behav Immun 1998, 12:297-307.

10. Glaser R, MacCallum RC, Laskowski BF, Malarkey WB, Sheridan JF, KiecoltGlaser JK: Evidence for a shift in the Th-1 to Th-2 cytokine response associated with chronic stress and aging. J Gerontol A Biol Sci Med Sci 2001, 56:M477-482.

11. Sepa A, Frodi A, Ludvigsson J: Mothers' experiences of serious life events increase the risk of diabetes-related autoimmunity in their children. Diabetes Care 2005, 28:2394-2399.

12. Ascher $\mathrm{H}$ : Coeliac disease and type 1 diabetes: an affair still with much hidden behind the veil. Acta Paediatr 2001, 90:1217-1220.

13. Bao F, Yu L, Babu S, Wang T, Hoffenberg EJ, Rewers M, Eisenbarth GS: One third of HLA DQ2 homozygous patients with type 1 diabetes express celiac disease-associated transglutaminase autoantibodies. J Autoimmun 1999, 13:143-148.
14. Norris JM, Barriga K, Klingensmith G, Hoffman M, Eisenbarth GS, Erlich HA, Rewers M: Timing of initial cereal exposure in infancy and risk of islet autoimmunity. JAMA 2003, 290:1713-1720

15. Ziegler AG, Schmid S, Huber D, Hummel M, Bonifacio E: Early infant feeding and risk of developing type 1 diabetes-associated autoantibodies. Jama 2003, 290:1721-1728.

16. Ludvigsson JF, Ludvigsson J: Stressful life events, social support and confidence in the pregnant woman and risk of coeliac disease in the offspring. Scand I Gastroenterol 2003, 38:516-521.

17. Sepa A, Wahlberg J, Vaarala O, Frodi A, Ludvigsson J: Psychological stress may induce diabetes-related autoimmunity in infancy. Diabetes Care 2005, 28:290-295.

18. Ludvigsson JF, Ansved P, Falth-Magnusson K, Hammersjo JA, Johansson C, Edvardsson S, Ljungkrantz M, Stenhammar L, Ludvigsson J: Symptoms and Signs Have Changed in Swedish Children With Coeliac Disease. J Pediatr Gastroenterol Nutr 2004, 38:181-186.

19. Ostberg M, Hagekull B, Wettergren S: A measure of parental stress in mothers with small children: dimensionality, stability and validity. Scand J Psychol 1997, 38:199-208.

20. Ostberg M: Parental stress, psychosocial problems and responsiveness in help-seeking parents with small (2-45 months old) children. Acta Paediatr 1998, 87:69-76.

21. Wekerle C, Wall AM, Leung E, Trocme N: Cumulative stress and substantiated maltreatment: the importance of caregiver vulnerability and adult partner violence. Child Abuse Negl 2007, 31:427-443.

22. Dube C, Rostom A, Sy R, Cranney A, Saloojee N, Garritty C, Sampson M, Zhang L, Yazdi F, Mamaladze V, Pan I, Macneil J, Mack D, Patel D, Moher D: The prevalence of celiac disease in average-risk and at-risk Western European populations: a systematic review. Gastroenterology 2005, 128: S57-67.

23. Peters U, Schneeweiss S, Trautwein EA, Erbersdobler HF: A case-control study of the effect of infant feeding on celiac disease. Ann Nutr Metab 2001, 45:135-142.

24. Welander A, Tjernberg AR, Montgomery SM, Ludvigsson J, Ludvigsson JF: Infectious Disease and Risk of Later Celiac Disease in Childhood. Pediatrics, PMID: 20176673. Epub Feb 22, 2010.

25. Leigh B, Milgrom J: Risk factors for antenatal depression, postnatal depression and parenting stress. BMC Psychiatry 2008, 8:24.

26. Rothman K, Greenland S: Modern Epidemiology Philadelphia: LippincottRaven Publishers, 21998.

27. Graham NM, Douglas RM, Ryan P: Stress and acute respiratory infection. Am J Epidemiol 1986, 124:389-401.

28. Boscarino JA: Diseases among men 20 years after exposure to severe stress: implications for clinical research and medical care. Psychosom Med 1997, 59:605-614.

29. Sepa A, Ludvigsson J: Psychological stress and the risk of diabetesrelated autoimmunity: a review article. Neuroimmunomodulation 2006, 13:301-308.

30. Cronin CC, Shanahan F: Insulin-dependent diabetes mellitus and coeliac disease. Lancet 1997, 349:1096-1097.

31. Smyth DJ, Plagnol V, Walker NM, Cooper JD, Downes K, Yang JH, Howson JM, Stevens H, McManus R, Wijmenga C, Heap GA, Dubois PC, Clayton DG, Hunt KA, van Heel DA, Todd JA: Shared and distinct genetic variants in type 1 diabetes and celiac disease. N Engl J Med 2008, 359:2767-2777.

\section{Pre-publication history}

The pre-publication history for this paper can be accessed here: http://www.biomedcentral.com/1471-230X/10/106/prepub

\section{doi:10.1186/1471-230X-10-106}

Cite this article as: Mårild et al.: Psychological stress and coeliac disease in childhood: a cohort study. BMC Gastroenterology 2010 10:106. 